\title{
The determinant of a five-stage downstream oil supply chain: An empirical study of Ghana
}

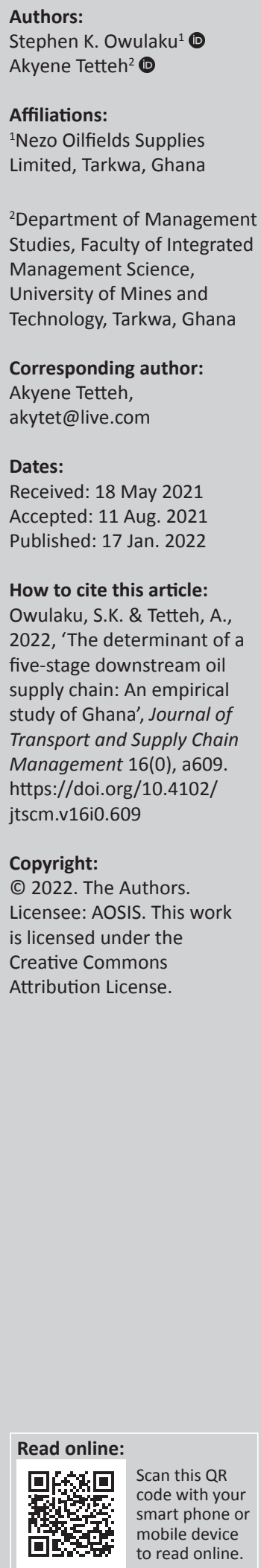

Background: The benefits derived from a downstream oil supply chain is very explicit and tangible. Various studies have looked at numerous determinants that drive the downstream oil supply chain, mainly among a specific player. However, the metamorphic nature of the industry powered by technological advancement, new policies, new oil well discoveries, and others raise an urgent need to assess the determinants of Ghana's downstream oil supply chain. Therefore, this article scrutinises the five-stage downstream oil supply chain from the Ghanaian perspective.

Objective: The key objectives of this study were to determine the determinant of a five-stage downstream oil supply chain and examine the impact of some of the identified determinants on the five-stage downstream oil performance.

Method: The study adopted a quantitative research approach, and a closed-ended questionnaire was used to collect primary data from five-stage downstream oil supply chain players. The data collected was screened, coded and complied in Microsoft excel and analysed statistically using Statistical Package for the Social Sciences (SPSS) 20. A preliminary test was conducted to ascertain the data distribution (mean and standard deviation [SD\}), reliability (Cronbach's alpha) and validity (ANOVA [analysis of variance]). The logistics regression was applied to examine the impact of the determinant on the five-stage downstream oil performance.

Results: The results suggest that government interference, human capital, collaborations, transportation issues amongst others are the determinants that affects the five-stage downstream oil supply chain. The logistics regression results revealed that each sector's performance contributes significantly to the sustenance of the five-stage supply chain. Besides, government interference (political stability and expand industry growth) and human capital (educational level and training programmes) are the factors that affect the five-stage downstream supply chain. But as for collaboration, none of the factors adopted affect the five-stage downstream oil supply chain.

Conclusion: In summary, the downstream oil supply chain player agrees that the sector's performance is steady within the entire chain. However, government interference significantly affects downstream oil supply chain performance negatively. Besides, players within the five-stage downstream supply chain neglect collaboration (trust, information sharing, enabling technology and incentive alignment) and pay less or no attention to cooperation which is the cornerstone of daily operational improvement of the five-stage downstream supply chain.

Keywords: five-stage downstream oil supply chain; collaboration; government interference; human capital; logistics regression.

\section{Introduction}

Ghana's oil and gas industry is divided into three sections: upstream (exploration, production, etc.), midstream (transport, logistics, etc.), and downstream (refinery, processing, distribution, etc.). The National Petroleum Authority (NPA) supervises the downstream industry, guided by Act 691, to supply environmentally sustainable oil and gas products. There are over 7000 key players (see Table 1) in the downstream oil industry in Ghana dealing with over 435968 metric tons of crude oil, 1.02 million metric tons of refined petroleum products (RPP), ${ }^{1}$ and contributed about $\$ 4.01$ billion (10\%) to Ghana's GDP in 2016 (NPA 2016). The introduction of the local content policy and participation regulation in 2013 and the deregulation policy in 2015 by the government (Acheampong, Ashong \& Svanikier 2016; Tawia 2018) have contributed to the massive growth of

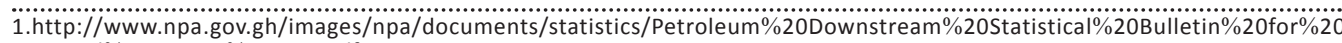
Second\%20Quarter\%202019.pdf 
the industry. The oil industry activities are crucial, and any disharmonies in its operations may cost the nation a vast sum of money.

The oil industry exhibits similar operations features, and extensive research has delved into the downstream oil determinants (Hussain, Assavapokee \& Khumawala 2006; Mbuguah, Kibuine \& Kahuthia 2019). Ofori (2015) concluded that the product's responsiveness and cost are the critical determinants required to improve the supply chain between oil marketing and bulk distribution companies in Ghana. The study by Tawia (2018) touched on determinants (traffic flow, buying area, accessibility, visibility, etc.) that affect fuel retailing sectors in Ghana, whilst Boison et al. (2018) studied the fuel retailing sector. They identified the location as the key determinant that influences sales volume. These works focused mainly on determinants that affect two players (supplier and manufacturers or distribution center and retailer) within the whole downstream oil industry.

Furthermore, the supply chain system is designed to deliver the right product at the right time and place. This suggests that the network of industries interacting in the downstream oil supply chain must always be in their best of performance in order not to shortchange refined petroleum product quality. Ofori (2015) asserted that delivery timeliness improves profitability, whilst Marwa (2016) affirmed that information sharing, collaboration, and stakeholder integration amongst industries within the downstream supply chain reduce inefficiencies and improve services. Osoro (2016) cautioned that any disruption within the downstream supply chain can submerge all the gains of the industry. Bimha, Hoque and Munapo (2017) revealed that compromising fuel supply results in a poor relationship between oil industries players. These authors acknowledged that the downstream oil supply chain determinant requires constant improvement to enable competitive advantage. However, over the 10 years of operation of the downstream oil industry in Ghana, not much literature has been dedicated to investigating downstream oil supply chain determinants. Moreover, the metamorphic nature of the industry powered by technological advancement, new policies, new oil well discoveries raise the urgent need to assess the determinants of Ghana's downstream oil supply chain. Therefore, this article assesses the determinants of the five-stage downstream oil supply chain in the context of Ghana. The objective stated is achieved by answering these questions: What are the determinants of the entire downstream oil supply chain? What is the impact of the identified determinants on the downstream oil supply chain performance?

\section{Literature review}

\section{Theoretical review}

The five-stage downstream oil supply chain starts with Tema Oil Refinery (TOR) receiving crude oil from Nigeria National Petroleum Corporation (NNPC) and oil imported from the neighbouring countries by the NPA. The TOR refines the crude oil into various useable refined petroleum products RPP (liquefied petroleum gas, gasoline, kerosene, diesel, aviation turbine kerosene, etc.). Since TOR's RPP capacity is limited, the Bulk Oil Storage and Transportation Company Limited (BOST) augments it with imported R.P.P. The total RPP is stored at various distribution centres at BOST sites all over the country. Oil marketing companies (OMC) access RPP from BOST distributing centres. They retail and distribute RPP to different filling stations across the country for easy customer access to the product (see Figure 1). The five-stage downstream oil supply chain starts with suppliers, manufacturers, distribution centres, retailers, and ends at filling stations. The activities taking place within the phases include; suppling of crude oil and RPP, transportation and distribution of RPP, an environmental problem with refinery of the oil, human capital receiving and accounting for RPP, government intervention, economic stability, stakeholder participation, customer satisfaction, tanks maintenance, dependency nature of the chain, etc. These activities give rise to the determinants (government interference, human capital, collaboration, transportation and distribution issues, environmental issues, maintenance issues, customer satisfaction, stakeholders, and economic issue) that affect the five-stage downstream oil supply chain industry. These determinants have theories that shape and guide them, like the resource-based view theory, political-economic theory, and stakeholder theory.

The resource-based view theory drives the dependency nature of the downstream players. The approach drew its source from strategic management and microeconomics, and was developed by Wernerfelt (1984) and Barney (1991). They emphasised that if a company wants to sustain a competitive advantage, it must possess valuable, rare, imperfectly imitable, and non-sustainable resources, which provides both tangible and intangible resources for the organisation to achieve its intended goal (Morali \& Searcy 2012; Sarkis, Zhu \& Lai 2011). In terms of tangible resources, any organisation can imitate it whilst intangible resources (company brand, intellectual property, etc.) act as the primary source for sustainable competitive advantage (Hitt, Carnes \& Xu 2016, cited in Nderitu \& Njuguan 2017). In building upon a company's competitive advantage, companies must collaborate with players within the supply chain since any delay retrogresses the advancement of competitive advantage. This collaboration advancement affirms the resource dependency theory, which suggests that 'in the supply chain, members should be dependent and collaborate to seek higher performance gain in the long-run instead of pursuing short-term benefits at the expense of the other' (Morali \& Searcy 2012; Sarkis et al. 2011).

The political economy theory draws its sources from economics, political science, law, history, and sociology to explain behaviour. The main focus is political factors such as the social relationship between organisations, power (government intervention, political tension), work ethics, etc., that affect oil industry work (Schnellenbach \& Schubert 2015, cited in 


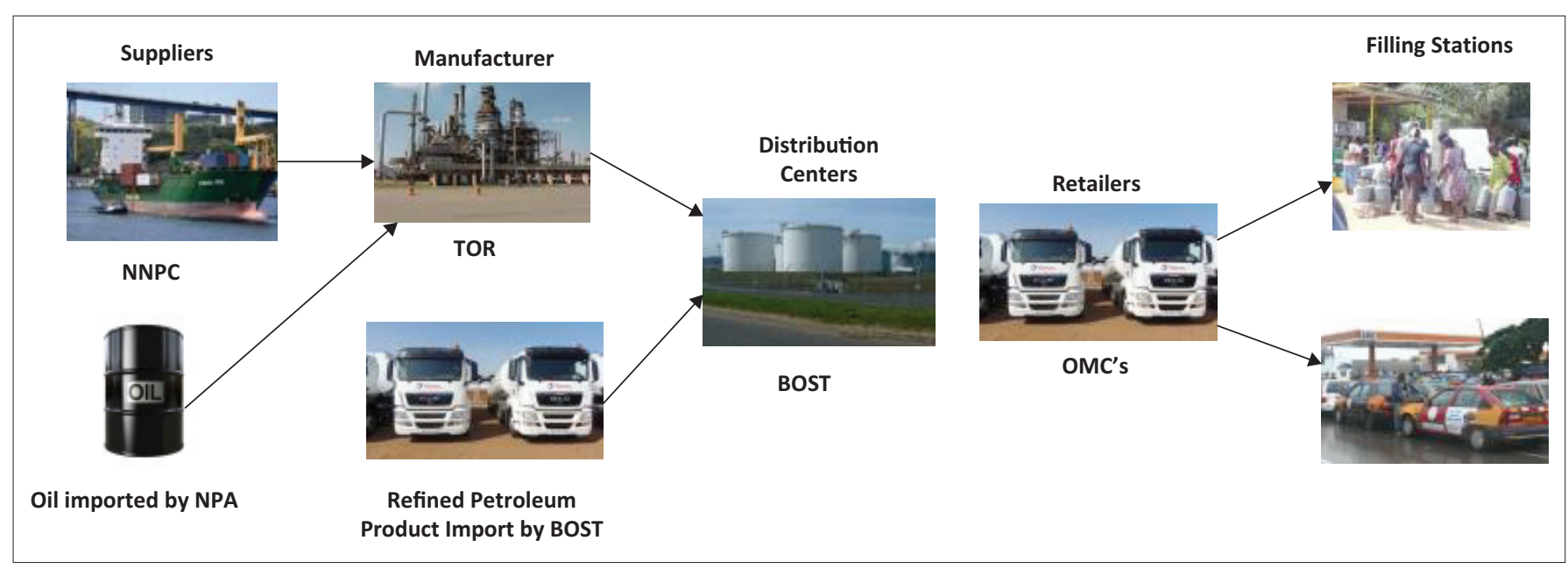

BOST, Bulk Oil Storage and Transportation Company Limited; NNPC, Nigeria National Petroleum Corporation; TOR, Tema Oil Refinery; OMC, oil marketing companies; NPA, National Petroleum Authority.

FIGURE 1: Downstream oil supply chain.

Mbuguah et al. 2019). Amponsah and Opei (2014) confirmed that government interference in the oil industry results in difficulties in paying under-recoveries and the high industry indebtedness. Therefore, government interference tends to retard the downstream oil industry progress. However, stakeholders' pressure, whether positive or negative, has an increased relevance for the industry. Freeman (2010) defined a stakeholder as 'any group or individual who can affect or is affected by the achievement of organization objectives'. Positive and negative externalities generated by stakeholders help downstream oil industries to achieve their set goals. That notwithstanding, stakeholders' externalities put immense pressure on the company's resources. This dilemma questions finding a lasting solution to externalities' cost and benefit (Morali \& Searcy 2012; Sarkis et al. 2011).

\section{Empirical review}

Extensive research is still ongoing to investigate downstream oil determinants. Bhaskaran and Sukumaran (2016) examined the determinant of value creation for the world's largest oil and gas companies. They used financial statements of 82 companies from 2009 to 2013, with average revenue of $\$ 39$ bn in 2013. Their result revealed that dividend policy and cost efficiency were the key determinants of a large oil company's valuation and that capital intensity negatively correlated with valuation. Chevillon and Rifflart (2009) worked on the physical market determinant of crude oil and market premium price. The study suggested that the critical biological market determinants are Organization of the Petroleum Exporting Countries (OPEC's) behaviour in controlling price, which often dwells on their market power and quotas and Organisation for Economic Co-operation and Development (OECD) expected future demand. Finally, Shobande (2018) investigated the determinants of downstream oil performance in Nigeria. Using panel data spanning 2000-2016, the author found that market structure is the critical determinant determining a firm's competitiveness. For oil companies to attain such a feat, he advised the Nigerian government to deregulate the downstream oil industry fully.
In Ghana, Amponsah and Opei (2017) explored supply chain challenges facing the downstream petroleum industry. They used questionnaires to collect their data and Statistical Package for Social Science (SPSS) to analyse the data. The results from this study suggested that government interference, government inability to pay under-recoveries, government indebtedness to players, inadequate infrastructure, and inconsistencies in refining crude oil by TOR are the key determinants slowing the industry progress. Atta-Kesson (2013) examined the factors driving the youth job expectations in an emerging oil hub, Western Region. He found that socio-cultural, political, economic factors and lack of local content policy hinder youth job expectations. Boison et al. (2018) looked into the factors influencing sales performance and a fuel station siting. They found that the fuel station location, branding, pump pricing, promotions, and service quality correlates with sales performance.

A critical retrospection on the empirical review revealed that intensive literature is available on the downstream oil industry. However, the focus of most of the literature is the primary determinant affecting a specific player in the downstream oil industry (Amponsah \& Opei 2017; AttaKesson 2013; Ofori 2015). This study deviates from earlier literature in such that it investigates the determinant affecting the whole downstream oil supply chain.

\section{Conceptual framework}

\section{Performance}

Luogon (2013) defined performance as 'the ability to provide a product as or more effectively and efficiently than relevant competitors'. A firm's performance can be measured using either its financials or non-financial. In terms of financial, return on asset, equity, and return on sales can be extracted from the firms' financial statement (Konar \& Cohen 2001, cited in Elsayed \& Paton 2005; Liargovas \& Skandalis 2010) to measure performance. For non-financials, balanced scorecard, innovation, quality, service, timely delivery, marketing expenditure, logistics management, and supply chain of the 
firm can measure a firm's performance (Kaplan \& Norton 1996; Omar, Waweru \& Rimiru 2015; Panjehfouladgaran et al. 2010; Robson 2005). From the preceding, this study measures performance using a non-financial, timely delivery of products within the downstream oil supply chain from the supplier to the retailer (see Figure 2).

\section{Government interferences}

From the political economy theory and Chapter 21 of the Ghana constitution, it will be challenging to say that Ghana's downstream oil industry is devoid of government interference. Amponsah and Opei (2015) concluded that government interference leads to disequilibrium in the demand and supply of RPP, delays in the payment of under-recoveries, and indebtedness to the downstream industry. Government interference is captured in this study by abuse of power, political stability (PS), perception, expansion of industry growth, and enlargement of industry risk. About abuse of power, the local content law states that in attaining a petroleum license, at most, $5 \%$ of the equity stake should be a Ghanaian indigenous firm. This law entrusted to the Minister of Petroleum ensures that other companies are selected when indigenous companies cannot meet the $5 \%$ requirement. It makes room for abuse of power and promotes conflict of interest. Ghana's PS has become a litmus paper for most African countries practising democracy. In a publication from the Denmark Embassy in Ghana, they described Ghana's PS as 'a two-decade of a stable democracy with a free and open election, comparatively low level of corruption and lack of border social instability'. ${ }^{2}$ As a result, Ghana has attracted foreign direct investment from all over the world, and has strong trading ties with the UK, the US, Asia, and Europe.

\section{Human capital}

The positive stakeholders' theory and Section 17 of Ghana's Local Content Policy stated that:

$[C]$ ontractors, subcontractors, licensees or other allied entities are to submit to the Petroleum commission detailed employment and training plans setting out the skills needed, anticipated skill shortage in the Ghanaian workforce, specific training requirement and timeframe for providing employment opportunities for Ghanaian for the phase of the petroleum activities.

Implying human capital growth is one of the core visions of Ghana's Local Content Policy, which the downstream oil industry cannot neglect. Marimuthu, Arokiasamy and Ismail (2009) defined human capital as the processes that relate to training, education and other professional initiatives to increase the level of knowledge, skills, abilities, values and social access of an employee, which leads to employee's satisfaction and performance and eventually business performance. Human capital is crucial for the development of every sector. The World Bank's World Development Report, 1998 titled 'Knowledge for Development' confirmed that the total wealth of 192

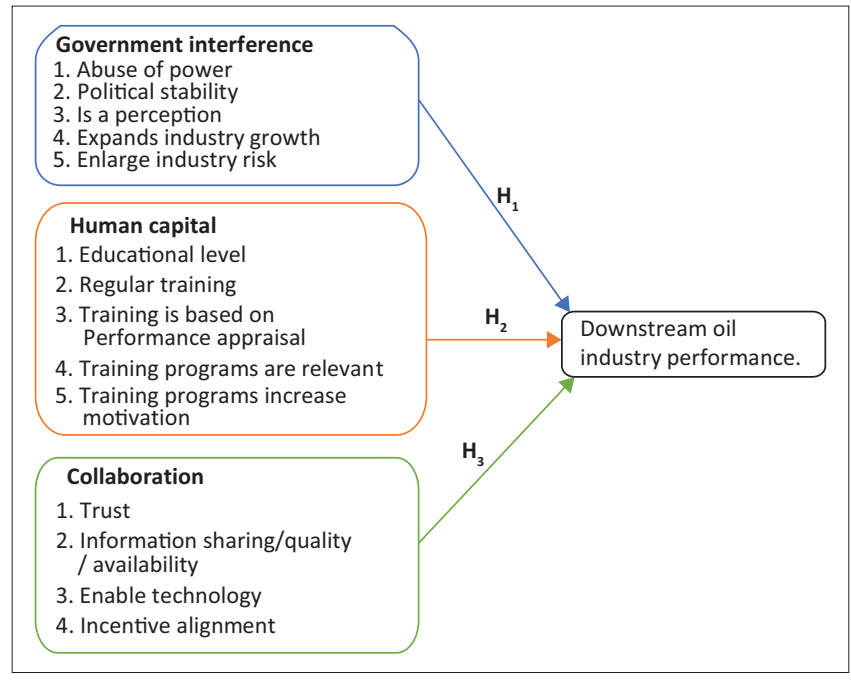

FIGURE 2: Conceptual framework.

countries is made up of $64 \%$ human capital, $16 \%$ physical capital, and $29 \%$ natural capital.

The Ministry of Energy (2011, cited in Arthur and Arthur 2014) pinpointed that Ghana's local content can develop based on the following four essential pillars: (1) education, (2) development of skills (training), (3) transfer of technology, and (4) active research and development. It is evidently clear that a well-executed local content policy leads to an educated workforce with the required requisite skills (training) who can use modern technology to conduct action research. Therefore, in this study, we measure human capital with the educational level of workers, regular in-house or outside training of workers, relevant training programmes, training programmes that increase workers' motivation, and training based on performance appraisal and worker familiarity with oil technology.

\section{Collaboration}

According to the resource dependency theory, without collaboration, the poor effectiveness of Figure 1 would increase the bullwhip effect of the downstream oil supply chain. Simatupang, Wright and Sridharan (2004) defined collaboration as 'a cooperative strategy of supply chain parties with a common goal of serving customer through integrated solutions for lowering cost and increasing revenue'. The importance of collaboration to a company includes; technology improvement, quick product development processes, reduce developmental cost, enhance product quality, knowledge sharing, effective governance, flexibility, sustainable competence, etc. (Walter 2003, cited in Hudnurkar, Jakhar \& Rathod 2014; Dyer \& Singh 1998; Nyaga, Whipple \& Lynch 2010). Hudnurkar et al. (2014) identified 28 factors that affect the collaboration of the supply chain. Meaning an improvement in these factors will boost the effectiveness and efficiency of the downstream oil and gas supply chain. This study adopts four (trust, information sharing, enable technology and incentive alignment) of these factors to analyse the downstream oil collaboration. 
Trust is positive confidence, attitude, or anticipation concerning the likelihood that another player's action will be satisfactory. This means that players in the industry hold each other in high esteem in terms of product quality and information accuracy. That notwithstanding, information sharing implies sharing essential or critical information among downstream oil players through every available communication medium. The main characteristics of such information are: accuracy, relevance, complete understanding, reliability, credibility, etc., that are held confidential and are timely available to all the players. Also, the downstream oil industry thrives on technology that can track products along the supply chain (Morton 2003, cited in Hussain et al. 2006). There is a wide range of technology available in the industry, including Compiere, WebERP, CRM, MIS, TPS, etc. Finally, the incentive alignment cushions and assures each player that in case of any unforeseen cost, risk and benefit, the players are willing to assist each other this assists downstream oil players in countering any unknown stress.

\section{Methodology}

This research approach adopted for this study is the quantitative method, utilising quantitative techniques (Creswell \& Creswell 2017). The study population consists of over 7000 key players (see Table 1) in the downstream oil industry in Ghana. For this population size, the purposive sampling technique was employed because it relies on the researcher's judgement in choosing a participant, it is time and cost-effectiveness, flexibility, facilitates easy selection of a participant, and supports the researcher's time frame (Saad et al. 2014, cited in Ofori 2015). However, it comes with specific weaknesses like participant and researcher biases. Using the sample size calculator ${ }^{3}$ with a population size of approximately 7000, a confidence level of $95 \%$, and an interval of $7 \%$ resulted in a sample size of 191 .

Primary data was collected using a closed-ended questionnaire. The questionnaire developed from the conceptual framework was distributed face-to-face to the participants in the downstream oil industry. The closedended questionnaire comprises eight key questions. Questions one and two deal with the participants' demographics, whilst question three identifies the downstream industry in which the participant works. Inquiry four dives into how long the participant has worked in the downstream oil industry. Question five measures the downstream oil industry performance using the variable of the timely delivery of crude oil/RPP. Questions six, seven and eight raise determinants (government interference, human capital and collaboration) that affect Ghana's downstream oil supply chain.

The primary data collected was screened, coded and compiled using Microsoft Excel and uploaded into SPSS software version 20 . The data investigation commenced by conducting a descriptive statistics (mean, standard deviation [SD], amongst others) to determine the data distribution.

3.https://www.surveysystem.com/sscalc.htm\#one
TABLE 1: Key player in the downstream oil and gas industry in Ghana.

\begin{tabular}{lc}
\hline Downstream players & Number \\
\hline Refinery company & 3 \\
Bulk distribution companies & 35 \\
Transport operators & 750 \\
Bulk road vehicles (BRVs) & 3674 \\
Oil marketing companies (OMCs) & 116 \\
LPG marketing companies (LPGMCs) & 42 \\
Retail outlets (filling stations) & 3867 \\
Export companies & 27 \\
Bunkering companies & 61 \\
Calibration companies & 12 \\
\hline Total & $\mathbf{8 5 8 7}$ \\
\hline
\end{tabular}

Source: Petroleum Downstream Statistical Bulletin, 2019, Second Quarter Publication, viewed n.d. from http://www.npa.gov.gh/Data/Documents/statistical-bulletin/2019/Petroleum\%20 Downstream\%20Statistical\%20Bulletin\%20for\%202nd\%20Quarter\%202019.pdf

It was followed by checking the reliability of the data by using Cronbach's alpha. The higher the Cronbach's alpha (> 0.70), the better the reliability (Zhu, Sarkis \& Lai 2008) of the questionnaire. Furthermore, we ran the one-way analysis of variance (ANOVA) to aid with data validity. After these preliminary tests, the logistics regression developed by Berkson in 1994 was used to regress each determinant factor against a dichotomous performance. Logistics regression strength lies in: it does not need pre-assumptions (Lee et al. 2015), achieves better accuracy compared to linear discriminant analysis (Harrell \& Lee 1985), and shows asymptotic characteristics (Green 2003, cited in Nandi et al. 2017). The logistics regression formulated is as follows:

$z_{i}^{*}=\beta_{0}+\sum_{i=1}^{m} \beta_{i j} X_{i j}+k_{i}$

[Eqn 1]

where $z^{*}$ i represents a latent variable (dichotomous performance) that is unobserved $z=0$ (Likert scale from 1 to 3 , implying downstream oil performance is decreased), and observed $z=1$ (Likert scale from 4 to 5 , meaning downstream oil performance is increased). $X_{i j}$ is a set of explanatory variables for each determinant, as shown in Table $2, \beta_{i j}$ are estimated coefficients, and $k_{i}$ is an error term.

The error term is supposed to follow a logistic distribution as defined in Equation 2. Equation 3 represents the empirical logistics model (where $p_{i}=$ prob $z_{i}=1$ ). For the logit or the $\log$ odds ratio (corresponding to the left-hand side), and the final model for each determinant factor (government interference, human capital and collaboration) refer to Equations 4, 5 and 6, respectively:

$F\left(q_{i}\right)=\frac{\exp \left(q_{i}\right)}{1+\exp \left(q_{i}\right)}$ [Eqn 2]

$\log \left\{\frac{p_{i}}{1-p_{i}}\right\}=\beta_{0}+\sum_{i=1}^{m} \beta_{i j} X_{i j}$ [Eqn 3]

$\log \left\{\frac{p_{i}}{1-p_{i}}\right\}=\beta_{0}+\beta_{1}($ gen $)+\beta_{2}(\mathrm{sec})+\beta_{3}(A o P)+$ [Eqn 4]

$\beta_{4}(P S)+\beta_{5}(I P e)+\beta_{6}(E I G)+\beta_{7}(E I R)$ 
$\log \left\{\frac{p_{i}}{1-p_{i}}\right\}=\beta_{0}+\beta_{1}($ gen $)+\beta_{2}(\mathrm{sec})+\beta_{3}(E L)+$

$\beta_{4}(R T)+\beta_{5}(T o A P)+\beta_{6}(T P a R)+\beta_{7}(T P i M)$

[Eqn 5]

$\log \left\{\frac{p_{i}}{1-p_{i}}\right\}=\beta_{0}+\beta_{1}($ gen $)+\beta_{2}($ sec $)+\beta_{3}($ Tru $)+$

[Eqn 6]

$\beta_{4}(I S Q A)+\beta_{5}(E T)+\beta_{6}(I A)$

\section{Results and discussions}

A total of 200 questionnaires were distributed to downstream oil and gas industry players, out of which 186 (representing 93\%) were returned. It can be observed from Table 2 that the mean of the data collected ranges from 0.60 (PER) to 4.50
(RT), whilst the SD that measures the data dispersion, ranges from 0.483 (GEN) to 1.303 (IPe). The questionnaire reliability was examined by Cronbach's alpha test: each Cronbach's alpha was more significant than 0.70 , with an overall average of 0.790. Also, the one-way ANOVA used to test the mean pairwise comparison between the variables was 242.82 ( $p$-value 0.000 ) significant at a $95 \%$ confidence level. The participants who took part in the study consist of males $(63.4 \%)$ and females $(36.6 \%)$, suggesting that the downstream oil industry is biased towards males'. Regarding the participant age, it was clear that the majority were in their youth, from 21 to 40 years of age (87.1\%), implying that the downstream oil and gas industry is still in its learning stage and has room for future growth. The majority of the sectors' key players participated in the study, as covered by the

TABLE 2: Descriptive statistics.

\begin{tabular}{|c|c|c|c|c|c|c|}
\hline Variable & Abbreviation & Mean & Standard deviation & Cronbach alpha $(\alpha)$ & Freq. & $\%$ \\
\hline Gender & GEN & 1.37 & 0.483 & 0.794 & - & - \\
\hline Male & - & - & - & - & 118 & 63.4 \\
\hline Female & - & - & - & - & 68 & 36.6 \\
\hline Age & AGE & 2.61 & 0.721 & 0.795 & - & - \\
\hline$<20$ years & - & - & - & - & 3 & 1.6 \\
\hline $21-30$ & - & - & - & - & 88 & 47.3 \\
\hline $31-40$ & - & - & - & - & 74 & 39.8 \\
\hline $41-50$ & - & - & - & - & 20 & 10.8 \\
\hline$>50$ & - & - & - & - & 1 & 05 \\
\hline Sector & SEC & 3.86 & 1.536 & 0.803 & - & - \\
\hline Refinery & - & - & - & - & 24 & 12.9 \\
\hline BOST & - & - & - & - & 18 & 9.7 \\
\hline Transportation & - & - & - & - & 20 & 10.8 \\
\hline OMC & - & - & - & - & 37 & 19.9 \\
\hline Filling Station & - & - & - & - & 72 & 38.7 \\
\hline Others & - & - & - & - & 15 & 8.1 \\
\hline Operational exitance & $\mathrm{OE}$ & 2.92 & 1.535 & 0.802 & - & - \\
\hline $1-5$ years & - & - & - & - & 45 & 24.2 \\
\hline $6-10$ & - & - & - & - & 46 & 24.7 \\
\hline $11-15$ & - & - & - & - & 19 & 10.2 \\
\hline $16-20$ & - & - & - & - & 31 & 16.7 \\
\hline$>20$ & - & - & - & - & 45 & 24.2 \\
\hline Performance & PER & 0.60 & 0.492 & 0.792 & - & - \\
\hline 0 & - & - & - & - & 75 & 40.3 \\
\hline 1 & - & - & - & - & 111 & 59.7 \\
\hline \multicolumn{7}{|l|}{ Government Interferences } \\
\hline Abuse of power & AOP & 4.13 & 1.080 & 0.779 & - & - \\
\hline Political stability & PS & 3.95 & 1.057 & 0.733 & - & - \\
\hline Is a perception & $\mathrm{IPe}$ & 2.99 & 1.303 & 0.787 & - & - \\
\hline Expands industry growth & EIG & 3.41 & 1.169 & 0.778 & - & - \\
\hline Enlarges industry risk & EIR & 3.09 & 1.211 & 0.784 & - & - \\
\hline \multicolumn{7}{|l|}{ Human Capital } \\
\hline Educational level & E.L. & 4.27 & 0.867 & 0.777 & - & - \\
\hline Regular training & R.T. & 4.50 & 0.692 & 0.778 & - & - \\
\hline Training is based on performance appraisal & ToPA & 3.77 & 1.020 & 0.775 & - & - \\
\hline Training programs are relevant & TPaR & 4.13 & 0.797 & 0.778 & - & - \\
\hline Training programs increase motivation & TPiM & 4.38 & 0.763 & 0.778 & - & - \\
\hline \multicolumn{7}{|l|}{ Collaborations } \\
\hline Trust & Tru & 4.18 & 0.811 & 0.772 & - & - \\
\hline Information sharing/ quality & ISQA & 4.31 & 0.728 & 0.775 & - & - \\
\hline Enable technology & ET & 4.12 & 0.925 & 0.777 & - & - \\
\hline Incentive alignment & IA & 4.37 & 0.810 & 0.775 & - & - \\
\hline
\end{tabular}

Note: Sample size, $N=186$; Overall Cronbach Alpha $(\alpha)=0.790 ;$ ANOVA $=242.82(0.000)$.

BOST, bulk oil storage and transportation company limited. 
various percentage distribution of the sectors confirmed with good operational experience. The performance data gathered using a Likert scale from 1 to 5 was converted to dichotomous data, unobserved 0 (covers 1, 2 and 3) with $40.3 \%$ frequency and observed 1 (covers 4 and 5) with 59.7\% frequency.

Tables 3, 4 and 5 touch on the impact of the investigated determinants on downstream oil supply chain performance. All the Tables reported significant positive values confirming that participants in the various industries of the downstream oil supply chain agree that performance is consistent within the oil supply chain. Table 3 reports on government interference impact on downstream oil supply chain performance. The diagnostics test showed that the Omnibus test and Hosmer and Lemeshow's test were both significant, signifying that the prediction model fit well with the data, and the overall classification analysis measuring the logit regression accuracy rate was average 69.9\% (unobserved performance 0 [52\%] and observed performance 1 [82\%]). The result suggests that PS decreases downstream oil supply chain performance. As PS deteriorates, it results in poor performance in the downstream oil supply chain. This result correlates with Mohen (2014, cited in Mbuguah et al. 2019) assertion that industries thrive under good PS. Meaning PS in Ghana is a catalyst to the downstream oil supply chain growth. On the other hand, the government's consistent effort to expand the downstream oil supply chain (EIG) may increase the downstream oil supply chain performance. This result demonstrates that Government of Ghana (GOG) timely policies (like local content, deregulation, participation regulation) are yielding the intended performance improvement of the industry (Acheampong et al. 2016; Arthur \& Arthur 2014; Tawia 2018).

Human capital impact on downstream oil supply chain performance is shown in Table 4. The diagnostics test for predicting the model fitness was significant when tested with Omnibus Test and was rejected by Hosmer and Lemeshow test, with an accuracy of classification of $69.4 \%$. The result revealed that the low educational level of workers within the downstream oil supply chain decreases the performance of the sector. On the other hand, as workers working within the downstream oil supply chain improve on their academic level, downstream oil supply chain performance may rise. The results affirm (Khan \& Afzal 2011; Ndulue 2012) that any organisation whose workers are skills and well-educated, enjoys solid organisational performance. Besides, training programme relevancy also showed a decreased impact on downstream oil supply chain performance. Indeed, training plays a crucial role in the human capital development of any organisation. However, if the content of the training programme is not relevant to the core needs of the job, it creates financial losses. That is why the GOG partners with international organisations and downstream supply chain operators to improve the content of the industry training (Ministry of Energy 2010, cited in Kazzazi \& Nouri 2012).

Finally, impact of the collaboration on downstream oil supply chain performance is covered in Table 5 . The diagnostics test revealed that the model prediction fitness was significant using the Omnibus and Hosmer and Lemeshow tests, with an average $(68.8 \%)$ classification accuracy. All the factors adopted were not substantial with downstream oil supply chain performance. Implying that collaboration benefits enjoyed by downstream oil supply chain players will elude the industry (Walter 2003, cited in Hudnurkar et al. 2014; Dyer \& Singh 1998; Eichmann 2000). Additionally, it presupposes that industry players reject trust, information sharing, enabling technology and incentive alignments in their operations. They are posing a difficult challenge on the aims, achievements and the stagnation nature of the industry. The results suggest that downstream oil supply chain players reject cooperative strategy among members.

\section{Conclusion}

The downstream oil supply chain contributed over $\$ 4$ bn to Ghana's GDP in 2016, housing over 7000 players in 10 key

TABLE 3: Government interference and downstream oil supply chain performance.

\begin{tabular}{lcccc}
\hline Variable & $\begin{array}{c}\text { Parameter } \\
\text { estimate }(\boldsymbol{\beta})\end{array}$ & Standard error & Wald statistics & Odd ratio $\left(\mathrm{e}^{\beta}\right)$ \\
\hline GEN & 0.258 & 0.342 & 0.571 & 1.295 \\
SEC & $0.388^{* * *}$ & 0.110 & 12.358 & 1.474 \\
AoP & -0.182 & 0.173 & 1.110 & 0.833 \\
PS & $-0.407^{* *}$ & 0.192 & 4.504 & 0.665 \\
IPe & -0.074 & 0.148 & 0.249 & 0.929 \\
EIG & $0.331^{*}$ & 0.185 & 3.190 & 1.393 \\
EIR & 0.037 & 0.151 & 0.061 & 1.038 \\
Constant & 0.133 & 0.979 & 0.018 & 1.142 \\
\hline
\end{tabular}

Note: Omnibus Test 28.252 (0.000); Hosmer and Lemeshow Test 8.482 (0.388); Overall Classification $69.9 \%$ [unobserved $0(52 \%)$ and observed $1(82 \%)$ ].

GEN, Gender; SEC, Sector; AoP, Abuse of power; PS, political stability; IPe, Is a perception EIG, Expands industry growth; EIR, Enlarges industry risk

$*$, significant level at $10 \% ; * *$, significant level at $5 \%$; ***, represent significant level at $1 \%$.

TABLE 4: Human capital and downstream oil supply chain performance.

\begin{tabular}{lcccc}
\hline Variable & $\begin{array}{c}\text { Parameter } \\
\text { estimate }(\boldsymbol{\beta})\end{array}$ & Standard error & Wald statistics & Odd ratio $\left(\mathbf{e}^{\beta}\right)$ \\
\hline GEN & 0.210 & $0 . .343$ & 0.373 & 1.233 \\
SEC & $0.430^{* * *}$ & 0.110 & 15.229 & 1.538 \\
EL & $-0.735^{* *}$ & 0.309 & 5.657 & 0.480 \\
RT & 0.399 & 0.347 & 1.327 & 1.491 \\
ToAP & 0.267 & 0.203 & 1.734 & 1.306 \\
TPaR & $-0.466^{*}$ & 0.272 & 2.930 & 0.672 \\
TPIM & 0.317 & 0.271 & 1.372 & 1.373 \\
Constant & -0.455 & 1.439 & 0.100 & 0.634 \\
\hline
\end{tabular}

Note: Omnibus Test 30.533 (0.000); Hosmer and Lemeshow Test 17.362 (0.027); Overall Classification $69.4 \%$ [unobserved $0(49.3 \%)$ and observed $1(82.9 \%)$ ].

GEN, Gender; SEC, Sector; EL, Educational level; RT, Regular training; ToAP, Training is based on performance appraisal; TPaR, Training programs are relevant; TPIM, Training programs increase motivation

$*$, significant level at $10 \% ; * *$, significant level at $5 \%$; ${ }^{* *}$, represent significant level at $1 \%$.

TABLE 5: Collaboration and downstream oil supply chain performance.

\begin{tabular}{lcccc}
\hline Variable & $\begin{array}{c}\text { Parameter } \\
\text { estimate }(\boldsymbol{\beta})\end{array}$ & Standard error & Wald statistics & Odd ratio $\left(\mathrm{e}^{\beta}\right)$ \\
\hline GEN & 0.073 & 0.330 & 0.048 & 1.075 \\
SEC & $0.425^{* * *}$ & 0.107 & 15.907 & 1.530 \\
Tru & -0.053 & 0.235 & 0.052 & 0.948 \\
ISQA & 0.136 & 0.254 & 0.287 & 1.145 \\
ET & -0.129 & 0.195 & 0.437 & 0.879 \\
IA & 0.009 & 0.235 & 0.001 & 1.009 \\
Constant & -1.132 & 1.210 & 0.874 & 0.322 \\
\hline
\end{tabular}

Note: Omnibus Test 18.982 (0.004); Hosmer and Lemeshow Test 8.726 (0.273); Overal Classification $68.8 \%$ [unobserved $0(44 \%)$ and observed $1(85.6 \%)$ ].

GEN, Gender; SEC, Sector; Tru, Trust; ISQA; Information sharing/quality; ET, Enable technology; IA, Incentive alignment

*, significant level at $10 \% ; * *$, significant level at $5 \%$; ${ }^{* *}$, represent significant level at $1 \%$. 
sectors (NPA, 2016). Various studies have extensively focused on downstream oil supply chain determinants but mainly concentrate on determinants that affect a player in the supply chain (Hussain et al. 2006; Mbuguah et al. 2019; Ofori 2015; Tawia 2018). This study looks at the determinant of a five-stage downstream oil supply chain in Ghana by answering these questions: What are the determinants of the five-stage downstream oil supply chain? What is the impact of the identified determinants on the downstream oil supply chain performance? In addressing these questions, three theories (resources-based view, political-economic and stakeholder) were used to shape and guide the study. The empirical review justified the study gap whilst the conceptual thinking enhanced the research goals. The conceptual framework was analysed using a quantitative research approach (Creswell \& Creswell 2017). Purposive sampling was used to sample the population size, and primary data was collected using closed-ended questions. The 186-questionnaire collected were screen, coded, and complied with Microsoft excel and uploaded into SPSS 20 for further preliminary investigations (mean, SD, Cronbach's alpha $(\alpha)$ and ANOVA). The logistics regression analysis was used to regress each determinant against a dichotomous performance.

The preliminary result indicates that the questionnaire is reliable (Cronbach's alpha $\alpha>0.7$ ) and valid (ANOVA 242.82 with a $p$-value of 0.000). It was found that the determinants that affects the five-stage downstream oil supply chain include: government interference, human capital, collaboration, transportation and distribution issues, environmental issues, maintenance issues, customer satisfaction issues, stakeholders and economic issues, and these issues address the first question of the article. The second question was answered by regressing three (government interference, human capital and collaboration) determinants against downstream oil supply chain performance. The results reveal that most downstream oil supply chain players agree that the sector's performance is steady within the entire chain. However, government interference factors (PS and expanding industry growth) significantly affect the performance of the downstream oil supply chain. Political stability negatively impacts the industry performance. As PS deteriorates, the industry performance dwindles, and as the national PS index improves, the industry performance grows (Mohen 2014 as cited in Mbuguah et al. 2019). Also, expanding industry growth increases the industry's performance. Besides, two human capital factors (educational level and training programme relevancy) had a significantly decreasing impact on downstream oil supply chain performance. Finally, none of the collaboration factors adopted had any significant impact on downstream oil supply chain performance. The result was intriguing, presupposing that downstream oil supply chain players neglect trust, information sharing, enabling technology and incentive alignment in their operations.

The article recommends that: the GOG should constantly improve on its PS index as its improvement impacts the industry performance positively, the GOG should regularly review the training content and educational requirement of the downstream oil supply chain industry, and downstream oil supply chain players should embrace trust, information sharing, enabling technology and incentive alignment in their operations. This research is limited by ' insufficient participants enthusiasm, difficulties in reaching downstream oil supply chain players, and lack of funds to target more participants. Further research should look at other identified determinants impacting the downstream oil supply chain, and other collaboration factors should be researched.

\section{Acknowledgements}

The authors would like to thank Dr Eric Neebo Wiah at the University of Mines and Technology for his immense contribution, correction, and time.

\section{Competing interests}

The authors declare that they have no financial or personal relationships, which may have inappropriately influenced them in writing this article.

\section{Authors' contributions}

This work was carried out in collaboration between all authors. S.K.O. aided with the data collection, arrangement of the manuscript and commented on the research, and A.T. designed the study, wrote the literature, carried out the analysis. Both authors read and approved the final manuscript.

\section{Ethical considerations}

This article followed all ethical standards for research without direct contact with human or animal subjects.

\section{Funding information}

This research received no specific grant from any funding agency in the public, commercial or not-for-profit sectors.

\section{Data availability}

Data sharing is not applicable to this article as no new data were created or analysed in this study.

\section{Disclaimer}

The views and opinions expressed in this article are those of the authors and do not necessarily reflect the official policy or position of any affiliated agency of the authors.

\section{References}

Acheampong, T., Ashong, M. \& Svanikier, V.C., 2016, 'An assessment of local-content policies in oil and gas producing countries', The Journal of World Energy Law \& Business 9(4), 282-302. https://doi.org/10.1093/jwelb/jww019

Amponsah, R. \& Opei, F.K., 2017, 'Ghana's downstream petroleum sector: An assessment of key supply chain challenges and prospects for growth', International Journal of Management and Business Studies 7(3), 441-448.

Arthur, P. \& Arthur, E., 2014, 'Local content and private sector participation in Ghana's oil industry: An economic and strategic imperative', Africa Today 61(2), 57-77. https://doi.org/10.2979/africatoday.61.2.57 
Atta-Kesson, R., 2013, 'Determinants of employment expectations of the youth in the emerging oil and gas industry in the Western Region of Ghana', Master's Dissertation, University of Ghana.

Barney, J.B., 1991, 'The resource-based view of strategy: Origins, implications, and prospects', Journal of Management 17(1), 97-211. https://doi.org/ 10.1177/014920639101700107

Bhaskaran, R.K. \& Sukumaran, S.K., 2016, 'An empirical study on the valuation of oil companies', OPEC Energy Review 40(1), 91-108. https://doi.org/10.1111/ opec.12064

Bimha, H., Hoque, M. \& Munapo, E., 2017, 'Supply chain management practices in the petroleum industry of Zimbabwe', International Business Management 11(12), 2210-2223.

Boison, K.D., Asamoah, H.Y., Addison, L. \& Asiedu, E., 2018, 'Assessing factors influencing sales performance and siting of a fuel station project: Study of Spintex road, Accra-Ghana', International Journal of Social Science and Humanities Research 5(4), 1268-1279.

Chevillon, G. \& Rifflart, C., 2009, 'Physical market determinants of the price of crude oil and the market premium', Energy Economics 31(4), 537-549. https://doi. org/10.1016/j.eneco.2009.01.002

Creswell, J.W. \& Creswell, J.D., 2017, Research design: Qualitative, quantitative, and mixed methods approaches, Sage publications, USA.

Dyer, J.H. \& Singh, H., 1998, 'The relational view: Cooperative strategy and sources of interorganizational competitive advantage', Academy of Management Review 23(4), 660-679. https://doi.org/10.5465/amr.1998.1255632

Eichmann, D.A., 2000, 'Creating a high-performance downstream petroleum supply chain', Achieving Supply Chain Excellence Through Technology, 229-232.

Elsayed, K. \& Paton, D., 2005, 'The impact of environmental performance on firm performance: Static and dynamic panel data evidence', Structural Change and Economic Dynamics 16(3),395-412. https://doi.org/10.1016/j.strueco.2004.04.004

Freeman, R.E., 2010, Strategic management: A stakeholder approach, Cambridge University Press, UK.

Harrell, F.E. \& Lee, K.L., 1985, 'A comparison of the discrimination of discriminant analysis and logistic regression under multivariate normality', Biostatistics: Statistics in biomedical, public health and environmental sciences', pp. 333-343, Statistics in biomedical, public heatth
Elsevier, New York, United States.

Hudnurkar, M., Jakhar, S. \& Rathod, U., 2014, 'Factors affecting collaboration in supply chain: A literature review', Procedia-Social and Behavioral Sciences 133, 189-202. https://doi.org/10.1016/j.sbspro.2014.04.184

Hussain, R., Assavapokee, T. \& Khumawala, B., 2006, 'Supply chain management in the petroleum industry: Challenges and opportunities', International Journal of Global Logistics \& Supply Chain Management 1(2), 90-97.

Kaplan, A.S. \& Norton, D.P., 1996, The balanced scorecard: Translating strategy into action, pp. 71-79, Harvard Business School Press, USA.

Kazzazi, A. \& Nouri, B., 2012, 'A conceptual model for local content development in petroleum industry', Management Science Letters 2(6), 2165-2174. https://doi. org/10.5267/j.msl.2012.05.031

Khan, M.A. \& Afzal, H., 2011, 'High level of education builds up strong relationship between organizational culture and organization performance in Pakistan', The International Journal of Human Resource Management 22(07), 1387-1400. https://doi.org/10.1080/09585192.2011.561955

Lee, Y.C., Hsiao, Y.C., Peng, C.F., Tsai, S.B., Wu, C.H. \& Chen, Q., 2015, 'Using Mahalanobis-Taguchi system, logistic regression, and neural network method to evaluate purchasing audit quality', Proceedings of the Institution of Mechanical Engineers, Part B: Journal of Engineering Manufacture 229(1 Suppl), 3-12. https://doi.org/10.1177/0954405414539934

Liargovas, P. \& Skandalis, K., 2010, 'Factors affecting firm competitiveness: The case of Greek industry', European Institute Journal 2(2), 184-197.

Luogon, A.G., 2015, 'Logistics management practices and performance of liquefied petroleum Gas firms in Kenya', Master's dissertation, pp. 1-77.

Marimuthu, M., Arokiasamy, L. \& Ismail, M., 2009, 'Human capital development and its impact on firm performance: Evidence from developmental economics', Journal of International Social Research 2(8), 265-272.
Marwa, B., 2016, 'Determinants of effective implementation of supply chain management practices in international humanitarian organizations in Kenya', Doctoral dissertation, pp. 1-95.

Mbuguah, M.N., Kibuine, M. \& Kahuthia, J., 2019, 'Effect of political violence disruptions on performance of the petroleum industry during electioneering period', International Academic Journal of Human Resource and Business Administration $3(6), 320-332$.
Adriod', International Academic

Morali, O. \& Searcy, C., 2013, 'A review of sustainable supply chain management practices in Canada', Journal of Business Ethics 117(3), 635-658. https://doi. practices in Canada', Journal of
org/10.1007/s10551-012-1539-4

Nandi, R., Bokelmann, W., Gowdru, N.V. \& Dias, G., 2017, 'Factors influencing consumers' willingness to pay for organic fruits and vegetables: Empirical evidence from a consumer survey in India', Journal of Food Products Marketing 23(4), 430-451. https://doi.org/10.1080/10454446.2015.1048018

National Petroleum Authority, 2016, Introduction to Ghana's Oil \& Gas Industry; history, current and future trends, viewed 16 October 2020, from http://www. gnpcghana.com/speeches/gnpcug.pdf.

Nderitu, D.M. \& Njuguna, R.K., 2017, 'The influence of retail network expansion on the competitive advantage of oil marketing firms in Kenya: Case of vivo energy', International Journal of Sales, Retailing and Marketing 6(2), 3-16.

Ndulue, T.I., 2012, 'Impact of training and development on workers performance in an organization', in Book of Proceedings, Proceedings of International Congress on Business and Economic Research (ICBER2012), International Association for Teaching and Learning, Granada, Spain, vol. 1, pp. 135-148.

Nyaga, G.N., Whipple, J.M. \& Lynch, D.F., 2010, 'Examining supply chain relationships: Do buyer and supplier perspectives on collaborative relationships differ?', Journal of Operations Management 28(2), 101-114. https://doi.org/10.1016/j. jom.2009.07.005

Ofori, C.G., 2015, 'An investigation into customer satisfaction along the oil supply chain in Ghana', Master's of Philosophy dissertation, University of Ghana.

Omar, A.S., Waweru, M. \& Rimiru, R., 2015, 'A literature survey: Fuzzy logic and qualitative performance evaluation of supply chain management', The International Journal of Engineering and Science (IJES) 4, 56-63.

Osoro, A., 2018, 'Challenges affecting performance of supply chain systems in the petroleum industry in Kenya', Doctoral dissertation, COHRED-JKUAT, pp. 1-276.

Panjehfouladgaran, H., Yusuff, R., Hong, T.S. \& Homayouni, S.M., 2010, ‘Qualitative performance measurement of supply chain management using fuzzy logic controller', in Proceedings of the 11th Asia Pacific Industrial Engineering and Managements System Conference, 7-10 December, Malacca, Malaysia

Petroleum Downstream Statistical Bulletin, 2019, Second Quarter Publication, viewed n.d. from http://www.npa.gov.gh/Data/Documents/statistical-bulletin/2019/ Petroleum\%20Downstream\%20Statistical\%20Bulletin\%20for\%202nd\%20 Quarter\%202019.pdf

Robson, I., 2005, 'Implementing a performance measurement system capable of creating a culture of high performance', International Journal of Productivity and Performance Management 54(2), 137-145. https://doi.org/10.1108/ 17410400510576621

Sarkis, J., Zhu, Q. \& Lai, K.H., 2011, 'An organizational theoretic review of green supply chain management literature', International Journal of Production Economics 130(1), 1-15. https://doi.org/10.1016/j.ijpe.2010.11.010

Shobande, A.O., 2018, 'Determinants of firms performance in Nigeria Oil and Gas Industry', Journal of Multidisciplinary Social Research, 44-51.

Simatupang, T.M., Wright, A.C. \& Sridharan, R., 2004, 'Applying the theory of constraints to supply chain collaboration', Supply Chain Management: An International Journal 9(1), 57-70. https://doi.org/10.1108/13598540410517584

Tawia, T.Y., 2018, 'Factors affecting the profitability of retail fuel outlets in urban areas: A case study of Accra', Master's dissertation, University of Cape Coast.

Wernerfelt, B., 1984, 'A resource-based view of the firm', Strategic Management Journal 5(2), 171-180. https://doi.org/10.1002/smj.4250050207

Zhu, Q., Sarkis, J. \& Lai, K.H., 2008, 'Green supply chain management implications for "closing the loop"', Transportation Research Part E: Logistics and Transportation Review 44(1), 1-18. https://doi.org/10.1016/j.tre.2006.06.003 